\title{
A HIDDEN MARKOV MODEL INFERENCE APPROACH TO TESTING THE RANDOM WALK HYPOTHESIS: EMPIRICAL EVIDENCE FROM THE Nigerian StOCK MARKET
}

\author{
Edesiri Nkemnole* \\ University of Lagos
}

Received: October 2015

Accepted: May 2016

\begin{abstract}
The movement of stock prices, in capital markets across the world, has been found to be both random and non-random. Basically, for a stock price to follow a random walk, its future price changes randomly based on all currently available information in the stock market, its price history inclusive. Some research findings have shown that the existing traditional unit root tests have low statistical power and hence cannot capture gradual changes over successive observations. Consequently, there is a need to revisit the random walk theory in stock prices using other tests. This study employs a Hidden Markov Model (HMM) with time-varying parameters to assess whether the stock price movements of the Nigerian Stock Exchange (NSE) follow a random walk process, or otherwise. Via hidden states, the HMM allows for periods with different volatility levels characterised by the hidden states. By simply accounting for the non-constant variance of the data with a two-state Hidden Markov Model and taking estimation into account via the Sequential Monte Carlo Expectation Maximisation (SMCEM) technique, this study finds no support of randomness. In conclusion, the stock price movements of the NSE do not follow the random walk process.
\end{abstract}

Keywords

Hidden Markov Model, random walk theory, stochastic volatility, stock exchange

*Dr EB Nkemnole is a senior lecturer in the Department of Mathematics, University of Lagos, Nigeria [enkemnole@unilag.edu.ng]. 


\section{INTRODUCTION}

Much effort have been put into developing and testing models of stock price index behaviour via random walk theory in finance, as well as empirical literature (Chung \& Hrazdil, 2010; Bariviera, 2011; Lin et al., 2011). Older studies favoured the random walk hypothesis (RWH) as it concerns empirical evidence (Fama, 1965; Niederhoffer \& Osborne, 1966). In a random walk hypothesis, all information contained in historical prices is rapidly reflected in the current market prices. This effectively impedes the opportunity to identify abnormal returns through a trend trading approach. However, some investment strategies are used to exploit trends in prices. In financial economics, the random walk hypothesis warrants further empirical analysis.

The Nigerian stock market is a regulated one; in other words, stock prices are not determined exclusively by the interactions between the forces of demand and supply. The stock prices are basically controlled by an enforced price band by the NSE, which inhibits prices from moving beyond $5 \%$ above and $5 \%$ below at the commencement of a trading day. Using data from stock markets in China, Korea and Taiwan, Lin et al. (2011) established that stock price limits affect stock price randomness. This finding corroborates the findings of Usman (1998) in Nigeria concerning the existence of price bands which limit the full effect of determinants on stock prices as share prices are barred from going beyond $5 \%$ above or $5 \%$ below the prevailing price on any trading day. The existence of influences in the market (Nwidobie, 2013), insider trading and slow pace of provision of market information to the market (Osaze, 2007), and the reliance of stock price determination and market information on previous periods resulted in the description of the Nigerian capital market as effective in the weak-form efficient, where the historical data and prices of the stocks are reflected in the current prices (Adelegan, 2003).

For Gordon (1959), stock values are determined by dividends paid in the immediate preceding period, the growth rate of the dividend and the equity capitalisation rate. Alteration in any of these variables results in a change in the price of that stock. Successive stock values vary as the values of these determinants vary. Fama (1965) maintained that the future price path of stocks is not determinate, as they move as numbers that are random. This movement, for Fama, is possible as the stocks reflect available information, suggesting that successive price changes are independent. This suggestion by Fama (1965) has been put to test in different capital markets across the world with varying outcomes.

This paper examines whether or not the Nigerian stock market is determined by random behaviour. The Augmented Dickey-Fuller (ADF) test and the Hidden Markov Model (HMM) with time-varying properties inference approach are used to study the random walk processes in stock prices.

\section{RELATED LITERATURE}

A lot of research has been done on the random walk of stock returns. I will look at the most relevant ones, as the scope of this study allows.

Research findings from tests for randomness in share price movement show varied recognised determinants of stock price randomness. One of the earliest works on the random movement of stock prices was by Kendall (1953). This work defines the basis for the random walk availability in the stock market prices, which has been tested and empirically evaluated by many researchers all over the world. However, some of them (e.g. Kapetanios et al., 2003; Hasanov \& Omay, 2007) find that stock prices prove unproductive in following the random walk, while a few of them confirm 
the existence of the random walk and a weak form market efficiency in developed, less developed and emerging stock markets of developed and underdeveloped nations.

Ma and Barnes (2001) used the serial correlation, runs and variance ratio tests to index and individual share data for daily, weekly and monthly frequencies. Their finding is that market indices and daily individual share prices in both the Shanghai and Shenzhen stock market demonstrate correlated return patterns, showing that B-shares' prices are more predictable than those of A-shares.

In their analysis of the random walk hypothesis for weekly stock returns, Lo and Mackinlay (1988) tested the RWH for weekly stock market returns by comparing variance estimators derived from data from 1216 sample observations at different frequencies. Their discoveries unequivocally rejected the random walk model for the sample period (1962 to 1985) and for all sub-periods for a variety of aggregate returns indexes and size-sorted portfolios. Keim and Stambaugh (1986), in a bid to refute the suppositions of the random walk theory, realised statistically important predictions of stock prices using predetermined variables. For Fama and French (1987), there is negative serially correlated relationship for long holding-period returns, their conclusion being that $25 \%-40 \%$ of longer horizon returns seem predictable from past returns. This is not in agreement with the findings of Lo and Mackinlay (1988) on the existence of a significant positive serial correlation for weekly and monthly holding-period returns. Al-Loughani (1995), through his application of different statistical devices on the Kuwait stock market (KSM), concluded that KSM does not follow the random walk, as it demonstrates rigidity in its results. Song and Weigen (1995) used the average returns of 29 stocks listed on the Shanghai Stock Exchange (SSE). This study revealed that the SSE is weak over the period of 1993 to 1994.

Wu (1996) assessed the weak-form proficiency of the Shanghai and Shenzhen stock markets, and did not discover weak form efficiency at the bottom line. Dahel and Laabas (1999) studied the efficiency of Gulf Cooperation Council (GCC) equity markets, using data from 1994 to 1998. Their conclusion is that the stock market of Kuwait follows the weak form of efficiency. Abraham et al. (2002) tested the RWH and market efficiency supposition for Saudi Arabia, Kuwait and Bahrain. The findings indicated that Saudi and Bahraini markets follow the hypothesis of random walk, but the market of Kuwait is inefficient and hence did not follow the RWH.

Malkiel (2003) avers that in the case of wholly efficient markets, the present period is not realised by past information. However, the investors are not permitted by the efficient stock markets to get more average returns without facing more average risks. Narayan and Smith (2004), Zivot and Andrews (1992) and Lumsdaine and Papell's (1997) have investigated the effects of structural breaks on the unit root tests process respectively to analyse the random walk hypothesis for stock prices in South Korea.

The findings of this study report that stock prices in South Korea have unit root, hence are consistent with the RWH. Liu (2010) examines the stock market development and market efficiency in the China Stock Market (CSM). By applying the EGARCH test, the study reveals that the CSM is not weak form efficient and does not follow the RWH. Zaubia and Nahlehb (2010) investigated the financial market efficiency in Middle East and North African countries (MENA). The outcome of this study showed that MENA markets follow the RWH and are efficient weakly.

Andersson (2007) opted to use hedging errors in option prices as a measure of the most suitable stochastic process. Through the use of the unit root test and the GARCH $(1,1)$, this study showed that these markets are not weak form efficient and do not follow the RWH. Ali and Mustafa (2001), employing the use of correlation coefficient of successive returns, averages, logarithms and 
regression analysis on daily price data of listed equities, tested this hypothesis in the Pakistani capital market and discovered that information collectively had an effect on stock prices, both negatively and positively. Lo and Mackinlay (1988) variance tests came up with inadequate inferences about the stock price index following a random walk at a fixed significance level. Though such tests can be applied to sequential time periods, they cannot really capture slow changes in efficiency over continual observations. Consequently, the need to re-examine the random walk theory in stock prices by means of other techniques is appropriate.

Research that has tried using other techniques includes Sharma and Kennedy (1977), Nakamura and Small (2007), Fifielda and Jetty (2008), and Borges (2011). Sharma and Kennedy (1977) used runs test and spectral technique to carry out a comparative study between the Bombay Stock Exchange (BSE) and the NySE; they discovered that monthly returns on the BSE were characterised by random walk. Nakamura and Small (2007) used the small-shuffle surrogate method to ascertain random walk characters in the US and Japanese stock returns. Fifielda and Jetty (2008) used parametric and non-parametric variance ratios on the daily data of 370 shares from 19962005 to examine the Chinese A-shares and B-shares market; their findings indicated that random price movements occur.

Globally, the Hidden Markov Models (HMMs) are the most prevalent methods in the machine learning and statistics for modelling sequences. In a statistics framework, the HMM is a composition of two stochastic processes: a Hidden Markov chain, which accounts for temporal variability, and an observable process, which accounts for spectral variability. The combination contains uncertainty status, just like the stock walk trace. Hence, the HMM and the stock walk trace have the same idea by coincidence.

For more than three decades, the HMM has been applied in signal-processing applications, especially in automatic speech recognition. But currently, this theory and application has been extended to other fields. A good example is Kim et al. (1998) who applied the HMM to examine the effects in economic data.

In this study, we will make new use of the HMM to test whether or not the daily returns of the Nigerian Stock Exchange (NSE) from 2010-2014 follow a random walk process.

\section{METHODS}

In this section the models used to explore the random walk are discussed.

\subsection{The Random Walk Model}

The Random Walk Theory holds that in financial markets, prices advance randomly and are not linked. Consequently, the patterns and trends of price changes in a market cannot be used to forecast the future value of financial instruments. More specifically, market efficiency under the random walk model entails that successive price changes of a stock are independently and identically distributed, so the past movement or trend of a stock price or market cannot be used to predict its future movement.

The random walk model due to Campbell et al. (1997) is defined as

$$
x_{t}=x_{t-1}+\varepsilon_{t}, \cdots \xi_{t} \sim \text { i.i.d. }\left(0, \sigma_{t}^{2}\right)
$$


and the increment is defined as

$$
y_{t}=x_{t}-x_{t-1}
$$

$\left\{x_{t}\right\}$ is the process, $\xi_{t}$ is distributed with mean zero and variance $\sigma_{t}^{2}$ and $\left\{y_{t}\right\}$ is the increment sequence.

\subsection{HMM approach with time varying parameters}

Although originally introduced and studied in 1957 and the early 1970s, the contemporary reputation of statistical methods of the HMM is not in question. An HMM is a bivariate discretetime process $\left\{X_{k}, Y_{k}\right\}_{k \geq 0}$ where $\left\{X_{k}\right\}_{k \geq 0}$ is a homogeneous Markov chain which is not directly observed but can only be observed through $\left\{Y_{k}\right\}_{k \geq 0}$ that produce the sequence of observation.

$\left\{Y_{k}\right\}_{k \geq 0}$ is a sequence of independent random variables such that the conditional distribution of $Y_{k}$ only depends on $X_{k}$. The underlying Markov chain $\left\{X_{k}\right\}_{k \geq 0}$ is called the state.

HMMs are defined through a functional representation known as the state space model. The state space model (Doucet \& Johansen, 2009) of an HMM is represented by the following two equations:

(State equation)

$$
x_{t}=f\left(x_{t-1}\right)+w_{t}
$$

(Observation equation)

$$
y_{t}=g\left(x_{t}\right)+v_{t}
$$

where $f$ and $g$ are either linear or nonlinear functions, while $w_{t}$ and $v_{t}$ are error terms. Models represented by (3) - (4) are referred to as state space models and this comprises a class of HMMs with non-linear Gaussian state-space models, for instance, the stochastic volatility (SV) model.

SV model (see Shephard, 1996, for a review) are a variant of the general state space approach presented here. The model belongs to the class of HMM with a non-linear Gaussian state-space model.

The SV model presented by Taylor $(1982,1986)$ accounts for the time-varying parameters and identifies changes towards/from the random walk. The model due to Taylor (1982) can be expressed as an autoregressive (AR) process:

$$
\begin{aligned}
& x_{t}=\phi x_{t-1}+w_{t} \\
& r_{t}=\beta \exp \left(\frac{x_{t}}{2}\right) v_{t}
\end{aligned}
$$

where $w_{t} \sim N(0, \tau), x_{0} \sim N\left(\mu_{0}, \sigma_{0}^{2}\right), v_{t} \sim N(0,1), x_{0}$ is the initial state variable (volatility) at time zero, $\left\{r_{t}\right\}_{t \geq 0}$ is the log-returns on day $t$, we call $\beta$ the constant scaling factor, so that $\left\{x_{t}\right\}_{t \geq 0}$ represents the log of volatility of the data, $\log \left(\sigma_{0}^{2}\right)$ where $\sigma_{0}^{2}=\operatorname{var}\left(r_{t}\right)$.

In order to ensure the stationarity of $r_{t}$, it is assumed that $|\phi|<1 . \phi$ is the autoregressive coefficient ranging from -1 to $l$ for stationarity. Clearly, $\phi$ when reaches one it becomes a random walk model. 
Taking the logarithm of the squared returns of equation (6) results in a linear equation (7),

$$
y_{t}=\alpha+x_{t}+z_{t}
$$

Equations (5) \& (7) form the version of the SV model, which can be modified in many ways; together they form a linear, non-Gaussian, state-space model for which (7) is the observation equation and (6) is the state equation.

$\{\phi, \tau, \alpha\}$ are parameters needed to model the changing volatility. The model integrates an error process in which the variance changes methodically over time. Hence, the model can detect gradual departures from the random walk through time. The mean of the log return depends on its conditional variance. A Sequential Monte Carlo with Expectation Maximisation (SMCEM) technique based on student-t distribution is used to estimate the model. The SMCEM sequentially updates coefficient estimates and generates the set of the parameters and their standard errors (see Kim \& Stoffer, 2008; Nkemnole \& Abass, 2015).

An extension of the linearised version of the SV model (see equations (5) and (7), wherein it is assumed that the observational noise process, $z_{t}$ is a student- $t$ distribution) is considered. The model, first presented in Shumway and Stoffer (2006), retains the state equation for the volatility as

$$
x_{t}=\phi x_{t-1}+w_{t}
$$

but the proposed student- $t$ distribution with degrees of freedom, $v$, for the observation error term, $z_{t}$, effects a change in the observation equation:

$$
y_{t}=\alpha+x_{t}+z_{t}, \quad z_{t} \sim t_{v}, t=1, \cdots, n
$$

For the parameter estimates of the proposed SV model with student- $t$, the likelihood functions have been maximised by using the Sequential Monte Carlo Expectation Maximisation algorithm (Nkemnole et. al., 2014) in the MATLAB optimisation routines.

\subsubsection{Sequential Monte Carlo Expectation Maximisation (SMCEM) Algorithm Analysis - Estimation procedures}

The entire estimation procedure consists of three main steps: filtering, smoothing, and estimation. With the output of filtering and smoothing step an approximate expected likelihood is calculated. $\{\phi, \tau, \alpha\}$ are estimated to model the changing volatility.

\subsubsection{Filtering Step}

The algorithm for the filtering and smoothing steps shows an extension of Godsill et al. (2004) and Kim and Stoffer (2008). From here $M$ samples from $f\left(x_{t}, \mid Y_{t}\right)$ for each $t$ were obtained.

Generate $f_{0}^{(i)} \sim N\left(\mu_{0}, \sigma_{0}^{2}\right)$ for $t=1, \cdots, n$.

Generate a random number $w_{t}^{(i)} \sim N(0, \tau), \quad j=1, \cdots, M$.

Compute $p_{t}^{(i)}=\phi f_{t-1}^{(i)}+w_{t}^{(j)}$.

a. Compute $w_{t}^{(i)}=p\left(y_{t} \mid p_{t}^{(i)},\right) \propto e^{-\frac{x_{t}}{2}}\left(1+\frac{y_{t}^{2} e^{-x_{t}}}{v-2}\right)^{\frac{v+1}{2}}$ 
b. Generate $f_{t}^{(i)}$ by resampling with weights, $w_{t}^{(j)}$.

\subsubsection{Smoothing step}

In the smoothing step, particle smoothers that are needed to get the expected likelihood in the expectation step of the $\varepsilon M$ algorithm were derived:

Suppose that equally weighted particles $\left\{f_{t}^{(i)}\right\}, i=1, \cdots, M$ from $f\left(x_{t}, \mid Y_{t}\right)$ are available for $t=1, \cdots, n$ from the filtering step.

Choose $\left[s_{n}^{(i)}\right]=\left[f_{n}^{(j)}\right]$ with probability $\frac{1}{M}$.

For $n-1$ to 0

Calculate

$w_{t \mid t+1}^{(i)} \propto f\left(s_{t+1}^{(i)} \mid f_{t}^{(j)}\right) \propto \exp \left(-\frac{\left(s_{t+1}^{(i)}-\phi f_{t}^{(j)}\right)^{2}}{2 \tau}\right) \frac{1}{\sqrt{\pi(v-2)}} \frac{\Gamma\left[\frac{v+1}{2}\right]}{\Gamma \frac{v}{2}} \exp ^{-\frac{\tilde{s}_{t+1}}{2}}\left(1+\frac{y_{t}^{2} e^{-\tilde{s}_{t+1}^{(j)}}}{v-2}\right)^{-\frac{v+1}{2}}$

for each $j$

Choose $\left[s_{t}^{(i)}\right]=\left[f_{t}^{(j)}\right]$ with probability $w_{t \mid t+1}^{j}$.

$\left(s_{0: n}^{(i)}\right)=\left\{\left(s_{0}^{(i)}, \cdots, s_{n}^{(i)}\right)\right\}$ is the random sample from $f\left(x_{0}, \cdots, x_{n} \mid Y_{n}\right)$

Repeat $1-3$, for $i=1, \cdots, M$ and calculate

$$
\begin{aligned}
& \hat{x}_{t}^{n}=\frac{\sum_{i=1}^{M} s_{t}^{(i)}}{M}, \hat{p}_{t}^{n}=\frac{\sum_{i=1}^{M}\left(s_{t}^{(i)}-\hat{x}_{t}^{n}\right)^{2}}{M-1}, \hat{p}_{t, t-1}^{n}=\frac{\sum_{i=1}^{M}\left(s_{t}^{(i)}-\hat{x}_{t}^{n}\right)\left(s_{t-1}^{(i)}-\hat{x}_{t-1}^{n}\right)}{M}, \\
& E\left[1+\frac{y_{t}^{2} e^{x_{t}}}{v-2}\right]^{-\frac{v+1}{2}}=\frac{n(v-2)}{(v+1) \sum_{t=1}^{n} y_{t}^{2} e^{-y_{t}+v_{t}}\left[1+\frac{y_{t}^{2} e^{x_{t}}}{v-2}\right]^{-1}}
\end{aligned}
$$

\subsubsection{Estimation Step}

This step consists of obtaining parameter estimates by setting the derivative of the expected likelihood, of the complete data $\left\{x_{0}, \cdots, x_{n}, y_{1}, \cdots, y_{n}\right\}$ given $\left\{x_{0}, \cdots, x_{n}\right\}$, with respect to each parameter to zero and solving for $\hat{\phi}, \hat{\tau}$, and $\hat{\alpha}$.

The complete likelihood of $\left\{x_{0}, x_{1}, \cdots, x_{n}, y_{1}, \cdots, y_{n}\right\}$ is 


$$
\begin{aligned}
& \log f(X, Y)=\log \frac{1}{\sqrt{2 \pi}} \frac{1}{\sigma_{0}}+\log \exp \left(-\frac{\left(x_{0}-\mu_{0}\right)^{2}}{2 \sigma_{0}^{2}}\right)+\log \prod_{t=1}^{n} \frac{1}{\sqrt{2 \pi \tau}} \exp \left(\frac{-\left(x_{t}-\phi x_{t-1}\right)^{2}}{2 \tau}\right) \\
&+\log \prod_{t=1}^{n} \frac{1}{\sqrt{\pi(v-2)}} \frac{\Gamma\left(\frac{v+1}{2}\right)}{\Gamma\left(\frac{v}{2}\right)} e^{-\frac{\left(y_{t}-\alpha-v_{t}\right)}{2}}\left(1+\frac{y_{t}^{2} e^{-\left(y_{t}-\alpha-v_{t}\right.}}{v-2}\right)^{-\frac{v+1}{2}}
\end{aligned}
$$

By the above method, we got the following estimates

$$
\begin{gathered}
\hat{\phi}=\frac{S_{10}}{S_{00}}, \quad \hat{\tau}=\frac{1}{n}\left[S_{11}-\frac{S_{10}^{2}}{S_{00}}\right] \\
\hat{\alpha}=\log \frac{n(v-2)}{(v+1) \sum_{t=1}^{n} y_{t}^{2} e^{-y_{t}+v_{t}}\left[1+\frac{y_{t}^{2} e^{x_{t}}}{v-2}\right]^{-1}} \\
\hat{\alpha}=\log \frac{n(v-2)}{(v+1) \sum_{t=1}^{n} y_{t}^{2} e^{-y_{t}+v_{t}}\left[1+\frac{y_{t}^{2} e^{x_{t}}}{v-2}\right]^{-1}}
\end{gathered}
$$

where

$$
\begin{aligned}
& S_{00}=\sum_{t=1}^{n}\left(x_{t-1}^{n}\right)^{2}+p_{t-1}^{n}, \\
& S_{11}=\sum_{t=1}^{n}\left(x_{t}^{n}\right)^{2}-p_{t}^{n}, \quad S_{10}=\sum_{t=1}^{n} x_{t}^{n} x_{t-1}^{n}+p_{t, t-1}^{n}
\end{aligned}
$$

\section{EMPIRICAL RESULTS AND DISCUSSION}

This section discusses data collection and analysis. Here, we will also discuss the results of the ADF tests to the random walk process. Lastly, results from the HMM model with time-varying parameters approach are also discussed and compared to the ADF tests.

\subsection{Data employed}

The sample data used for this study is drawn from the daily stock prices of five firms of the NSE, in Banking (GTB), Oil \& Gas (OANDO), Construction (Juius Berger), Health care (Glaxo Smith) and Industrial goods (Chemical \& Applied Product (CAP)) over the period 2 January 2010 to 31 December 2014. 
The data series is transformed into log returns series so that we get stationary series. The transformation is:

$y_{t}=\log \left(\frac{p_{t}}{p_{t-1}}\right)=\log \left(p_{t}\right)-\log \left(p_{t-1}\right)=p_{t}-p_{t-1}$

Where $p_{t}$ is the price of stock at time $t$.

A descriptive statistical summary is obtained to view the data for the daily stock prices and returns of all the indices.

TABLE 1 reports the descriptive statistics for all five selected indices. The positive skewness and kurtosis indicated non-normal series. With reference to Jarque-Bera statistics, the stock index series is non-normal at the confidence interval of $99 \%$, since probability is 0.000000 , which is less than 0.01 .

TABLE 1: Descriptive statistical summary for the daily stock prices

\begin{tabular}{lcccccc}
\hline Index & Mean & Std. Dev. & Skewness & Kurtosiss & Jarque-Bera & Probability \\
\hline GTB & 40.375 & 18.457 & 0.671 & 3.348 & 194.387 & 0.000 \\
OANDO & 70.974 & 47.483 & 1.029 & 4.844 & 202.394 & 0.000 \\
JBERGER & 46.888 & 25.541 & 0.993 & 4.256 & 207.281 & 0.000 \\
GLAXOSMITH & 76.987 & 48.253 & 1.154 & 4.234 & 213.237 & 0.000 \\
CAP & 49.34 & 27.377 & 0.278 & 3.684 & 195.142 & 0.000 \\
\hline
\end{tabular}

Source: Author's analysis

GTB

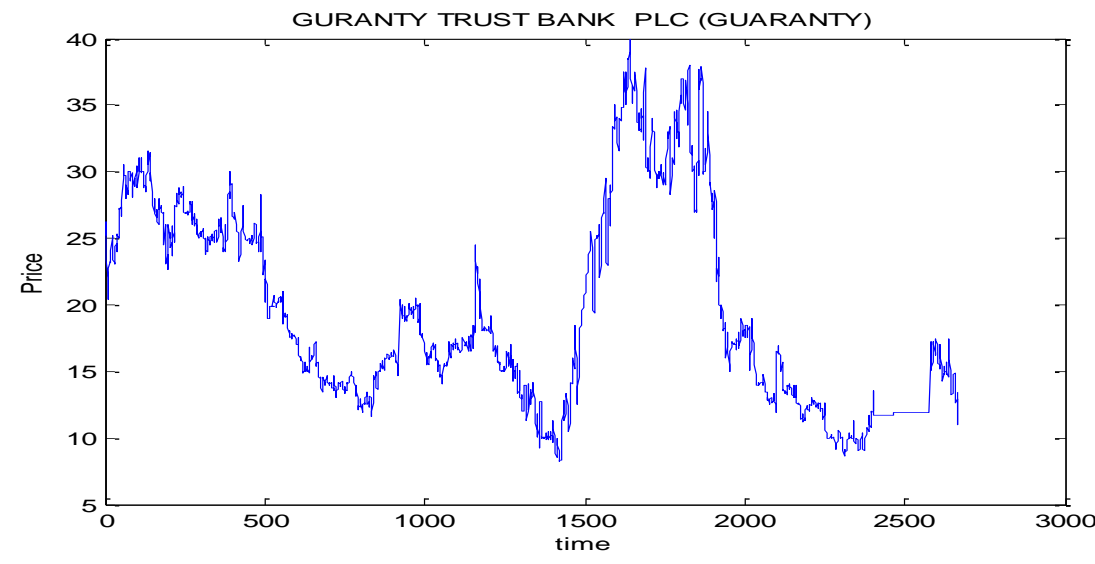


A HIDDEN MARKOV MODEL INFERENCE APPROACH TO TESTING THE RANDOM WALK HYPOTHESIS

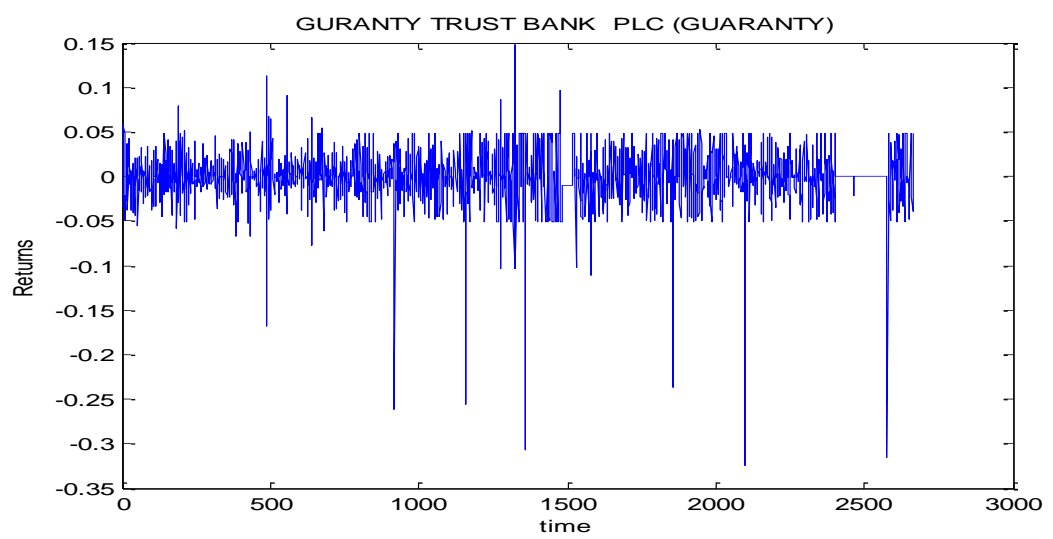

OANDO
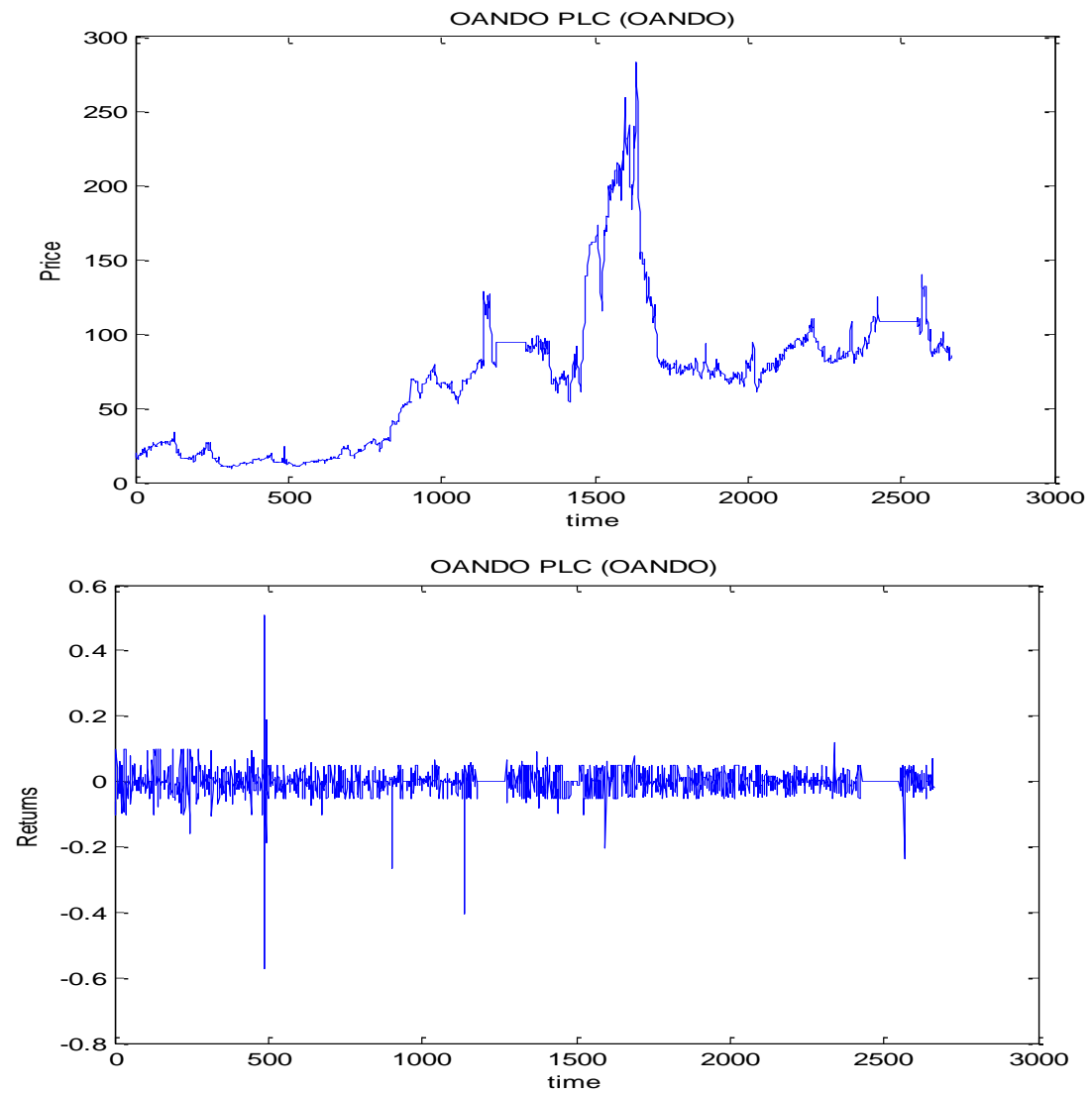
JBERGER
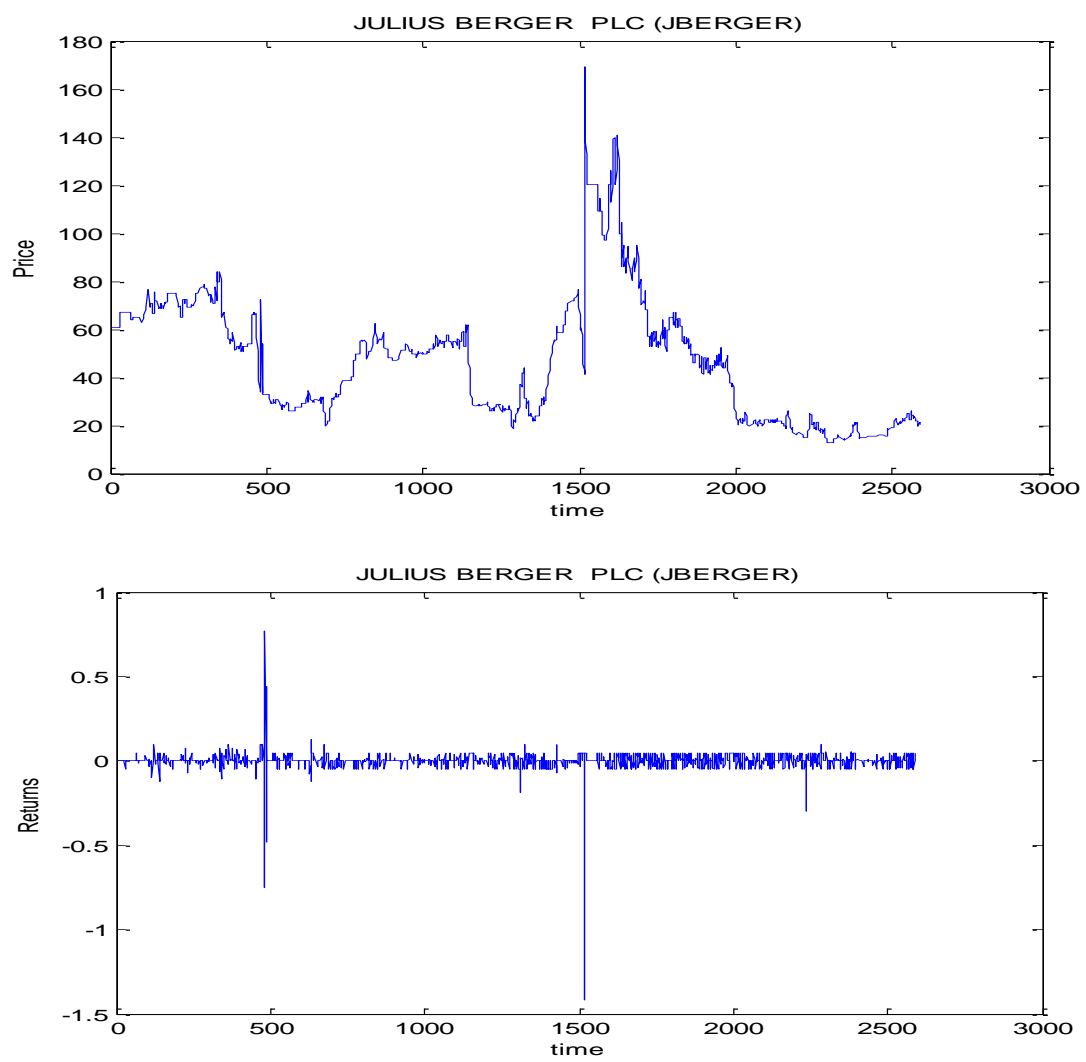

\section{GLAXOSMITH}

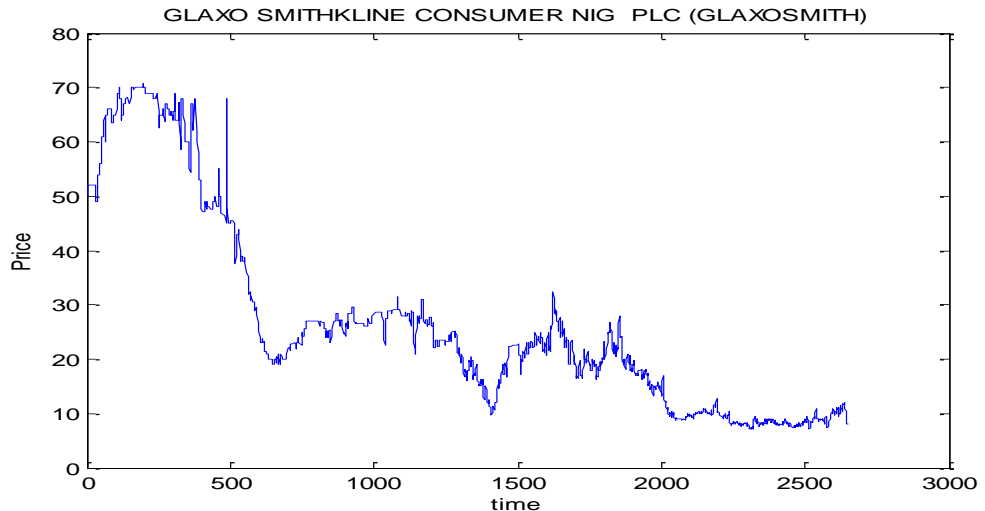




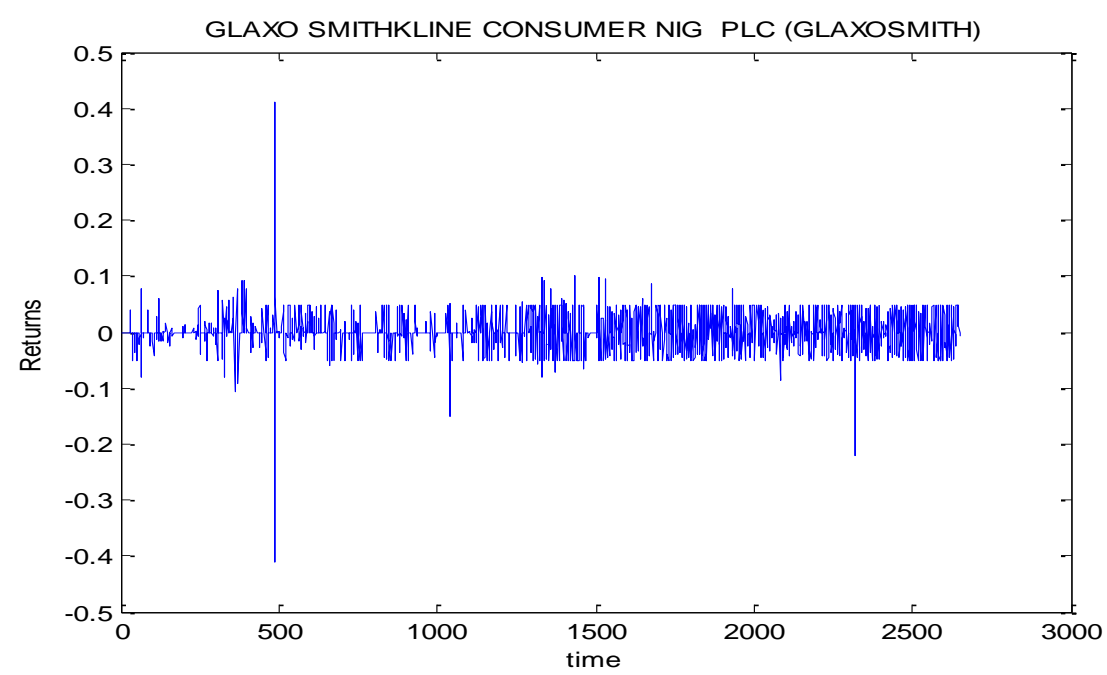

CAP
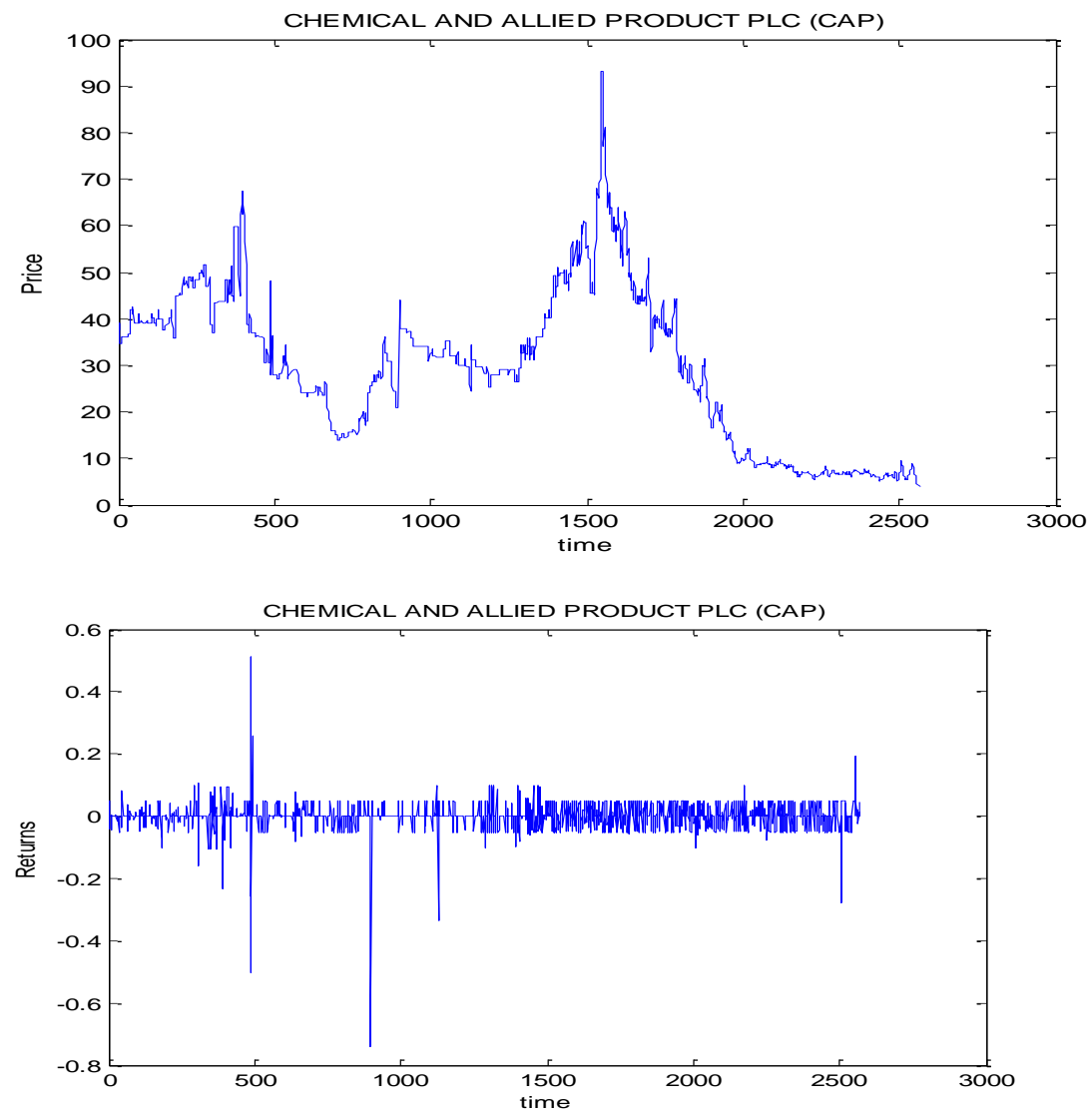

FIGURE 1: Plot for all the five selected stock prices and log returns 


\subsection{Transformation of the stock index series of the NSE}

On the whole, the movements of the stock indices series are non-stationary, and therefore not suitable for the purposes of this study. The stock indices series are transformed into their returns.

\subsubsection{Augmented Dickey-Fuller (ADF) Test}

The ADF test is used to obtain verification regarding whether the NSE return series is stationary or not.

TABLE 2: ADF test for NSE index

\begin{tabular}{|c|c|c|c|c|c|c|}
\hline \multicolumn{7}{|c|}{$\mathrm{t}$-Statistic } \\
\hline & & GTB index & $\begin{array}{l}\text { OANDO } \\
\text { index }\end{array}$ & $\begin{array}{l}\text { JBERGER } \\
\text { index }\end{array}$ & $\begin{array}{l}\text { GLAXOSMITH } \\
\text { index }\end{array}$ & CAP \\
\hline \multirow[t]{3}{*}{$\begin{array}{l}\text { ADF test } \\
\text { statistic }\end{array}$} & & -40.021 & -41.441 & -43.224 & -42.663 & -40.325 \\
\hline & $1 \%$ level & -4.752 & -4.657 & -4.031 & -4.812 & -4.412 \\
\hline & $5 \%$ level & -3.640 & -3.552 & -3.742 & -3.441 & -3.460 \\
\hline $\begin{array}{l}\text { Test } \\
\text { critical } \\
\text { values }\end{array}$ & $10 \%$ level & -3.665 & -3.566 & -3.406 & -3.456 & -3.44 \\
\hline Prob. & & 0.0001 & 0.0001 & 0.0001 & 0.0001 & 0.0001 \\
\hline
\end{tabular}

Source: Author's analysis

TABLE 2 shows that the values of the ADF test statistic of all the NSE index series $(-40.021,-41.441$, $-43.224,-42.663$, and -40.325$)$ are less than the test critical values $(-3.640,-3.552,-3.742,-$ 3.441 , and -3.460 respectively at the $5 \%$ level of significance), which implies that the NSE index series are stationary. Non-stationarity implies the random walk German (2007).

TABLE 3: Summary Statistics of the index returns series

\begin{tabular}{lcccccc}
\hline \multicolumn{1}{c}{ Index } & Mean & Std. Dev. & Skewness & Kurtosis & $\begin{array}{c}\text { Jarque- } \\
\text { Bera }\end{array}$ & Probability \\
\hline GTB & 0.003 & 0.027 & -2.473 & 29.468 & 684.195 & 0.000 \\
OAND0 & -0.001 & 0.035 & -1.303 & 54.496 & 312.573 & 0.000 \\
JBERGER & 0.004 & 0.045 & -1.554 & 42.651 & 497.263 & 0.000 \\
GLAXOSMITH & 0.007 & 0.030 & -0.191 & 30.232 & 513.240 & 0.000 \\
CAP & 0.001 & 0.037 & -3.678 & 20.794 & 795.142 & 0.000 \\
\hline
\end{tabular}

Source: Author's analysis

TABLE 3 reveals a negative skewness, and significant excess kurtosis for all the indices. With reference to the Jarque-Bera statistics, the stock index series is non-normal at the confidence interval of $99 \%$. 
As the actual volatility at time $t$ is not observable, there is need for some measures of volatility to assess the forecasting performance. In this paper we apply the standard approach suggested by Pagan and Schwert (1990). A proxy for the actual volatility $\hat{\sigma}_{t}^{2}$ is given by

$$
\hat{\sigma}_{t}^{2}=\left(r_{t}-\bar{r}\right)^{2}
$$

where $\bar{r}$ is the mean of the time series over the sample period. The statistical performance measures Mean Absolute Percentage Error (MAPE) are applied to see the predictive exactness.

$$
\text { MAPE }=\frac{\sum_{t=1}^{n}\left|\hat{\sigma}_{t}^{2}-\sigma_{t}^{2}\right| \div \sigma_{t}^{2}}{n}
$$

where $\hat{\sigma}^{2}$ is the forecasted variance and $\sigma^{2}$ the actual variance time period $t$ and $n$ is the number of forecasts.

\subsubsection{Statistical performance}

The evaluation results are shown in TABLES 4 and 5. A two-state HMM model was used in our experiments. In the table, $\mathrm{t}-\mathrm{v}$ represents true value, while $s_{1}$ and $S_{2}$ designate the two states with low and high volatility levels, respectively.

TABLE 4: Statistical performance results for the simulated data set and the true parameter sets compared with those obtained from HMM-SV

\begin{tabular}{ccccccc}
\hline \multicolumn{2}{r}{ Models } & $\boldsymbol{\phi}$ & $\boldsymbol{\tau}$ & $\boldsymbol{\alpha}$ & MAPE & p-values \\
\hline \multirow{2}{*}{$\mathrm{t}-\mathrm{v}$} & S1 & 0.63 & 0.850 & 2.166 & & \\
& S2 & 0.70 & 1.254 & 2.094 & & \\
\multirow{2}{*}{ HMMSV } & S1 & 0.64 & 1.365 & 2.146 & & \\
& S2 & 0.78 & 1.353 & 2.113 & 0.111 & 0.075 \\
\hline
\end{tabular}

Source: Author's analysis

TABLE 5: Statistical performance results from HMM-SV model

\begin{tabular}{lrrrrrr}
\hline Index & Model & $\boldsymbol{\phi}$ & $\boldsymbol{\tau}$ & $\boldsymbol{\alpha}$ & MAPE & $p$-values \\
\hline GTB & HMMSV S1 & 0.787 & 3.477 & 6.998 & & \\
& S2 & 0.068 & 1.234 & 3.874 & 0.067 & 0.041 \\
\hline \multirow{2}{*}{ OAND0 } & HMMSV S1 & 0.812 & 4.236 & 4.714 & & \\
& S2 & 0.071 & 3.113 & 2.134 & 0.071 & 0.038 \\
& & & & & & \\
\hline JBERGER & HMMSV S1 & 0.905 & 1.313 & 0.988 & & \\
\hline
\end{tabular}




\begin{tabular}{lrrrrrl}
\hline \multicolumn{1}{c}{ Index } & Model & $\boldsymbol{\phi}$ & $\boldsymbol{\tau}$ & $\boldsymbol{\alpha}$ & MAPE & p-values \\
\hline GLAXOSMITH & HMMSV S1 & 0.887 & 1.460 & 1.259 & & \\
\multirow{2}{*}{ CAP } & S2 & 0.076 & 1.360 & 1.159 & 0.095 & 0.023 \\
& HMMSV S1 & 0.869 & 2.151 & 0.765 & & \\
\hline & S2 & 0.065 & 1.353 & 1.159 & 0.096 & 0.010 \\
\hline
\end{tabular}

Source: Author's analysis

The above results show that that HMM model captures the volatility structure changes processes between two different volatility regimes with different volatility persistence $\boldsymbol{\phi}$ with $p$-values of $.041, .038, .031, .023$, and .010 for each of the stocks respectively. The parameter estimates are statistically significant at the $5 \%$ significance level. From the research results, we conclude that Nigerian stock prices do not follow the random walk pattern described by Fama (1965). Basically, the HMM-SV model offers better volatility forecasts, as the MAPE are 0.067, 0.071, 0.061, 0.0956 and 0.096 . Hence, the predictive exactness is high.

\subsection{Discussion}

In this paper, a HMM is introduced to test whether or not the daily returns of the Nigerian Stock Exchange (NSE) follow a random walk process.

The descriptive statistics for the five indices of the NSE are given in TABLE 3. The highest average returns are obtained in GLAXOSMITH. The JBERGER and GTB are the other indices, which show higher mean returns. This reflects the performance of these indices. Further, the JBERGER has the highest standard deviation (0.045), which represents higher volatility, while the lowest is of GTB (0.027). The returns of the five selected indices are negatively skewed, indicating that the returns are flatter to the left compared to the normal distribution. The significant kurtosis indicates that return distribution has sharp peaks compared to a normal distribution. The Jarque-Bera (1980) statistic confirmed that index returns are non-normally distributed.

The ADF test given in TABLE 2 for all the NSE index series indicates that the NSE index series are stationary. The ADF test statistic is less than its test critical value respectively at the $5 \%$ level of significance. Non-stationarity implies a random walk pattern (German, 2007).

This study demonstrates that the HMM model forecasts very well in the stock recognition domain. The model captures the volatility structure changes processes between two different volatility regimes with different volatility persistence $\phi$ with $p$-values of $.041, .0385, .0313, .0234$ and .0106 for each of the stock respectively (see TABLES 4 and 5). The parameter estimates are statistically significant at the $5 \%$ significance level. The HMM is highly accurate and the predictive exactness is high, as proved by the MAPE value, which is lower than $10 \%$.

Thus, the statistical performance results from the HMM reveal that the daily returns of the NSE do not follow the random walk pattern. This result corroborates the findings of Nwidobie (2014). The research findings also show that price of equities on the Nigerian Stock Exchange seem to follow a definite path determined by information about the stock and the issuing firms.

Based on the above outcome, it is pertinent that the regulatory authority and policy-making body ensure proper dissemination of information so that price can reflect the information promptly. 


\section{CONCLUSION}

Although we have a considerable amount of literature on random walk and market efficiency, there is no agreement among the scholars concerning random walk and efficiency of the market. Andersson (2007) is of the view that the traditional unit root tests have a low statistical power and that they cannot readily capture gradual changes over successive observations. In this research, a Hidden Markov Model (HMM) with time-varying properties is applied to test whether or not the stock price movements of the NSE follow a random walk process. The Augmented DickeyFuller (ADF) is employed to test for stationarity in the data set from 2 January 2010 to 31 December 2014. The HMM-SV model developed allows for periods with different volatility states in the time series and state-specific SV model within each state. By simply accounting for the non-constant variance of the data with a two-state HMM of student's distribution and taking estimation into account via the SMCEM technique, the empirical results confirm that the stock price movements on the NSE do not follow the random walk pattern described by Fama (1965) i.e. are not random. This result corroborates the findings of Nwidobie (2014), Kapetanios et al. (2003) and Lo and Mackinlay (1988; 1987).

\section{LIST OF REFERENCES}

Abraham, A., Fazal, J. \& Sulaiman, A. (2002). Testing the random walk behavior and efficiency of the gulf stock markets. The Financial Review, 37, pp. 469-480.

Adelegan, 0.J. (2003). Capital market efficiency and the effects of dividend announcements on share prices in Nigeria. African Development Review, 15(3), pp. 218-236.

Ali, S.S. \& Mustafa, K. (2001). Testing semi-strong form efficiency of stock market. The Pakistan Development Review, 40(4), pp. 651-674.

Al-Loughani, N.E. (1995). Random walk in thinly traded stock markets: The case of Kuwait. Arab Journal of Administration Science, 3, pp. 189-209.

Andersson, H.(2007). Are commodity prices mean reverting? Applied Financial Economics, 17, pp. 769783.

Bariviera, A.F. (2011). The influence of liquidity on informational efficiency. The case of the Thai stock market. Physica A, 390, pp. 4426-4432.

Borges, M.R. (2011). Efficient market hypothesis in European stock markets. The European Journal of Finance, 16(7), pp. 711-726.

Campbell, J.Y., Lo, A.W. \& Mackinlay, A.C. (1997). The Econometrics of Financial Markets. Princeton: Princeton University Press.

Chung, D. \& Hrazdil, K. (2010). Liquidity and market efficiency: A large sample study. Journa/ of Banking \& Finance, 34, pp. 2346-2357.

Dahel, R. \& Laabas, B. (1999). The behavior of stock prices in the GCC Markets. Journal of Development and Economic Policies, 1, pp. 89-105.

Doucet, A. \& Johansen, A.M. (2009). A Tutorial on Particle Filtering and Smoothing: Fifteen years later. In Crisan, D. \& Rozovsky, B. (eds.) Oxford Handbook of Nonlinear Filtering. Oxford University Press. (pp. 656-704). 
Fama, દ. (1965). The behavior of stock market prices. Journal of Business, 38, pp. 34-105.

Fama, દ. (1970). Efficient capital markets: A review of theory and empirical work. Journal of Finance, 25(2), pp. 383-417.

Fama, દ. \& French, K. (1987). Permanent and temporary components of stock prices. Working Paper No. 178. Centre for Research on Security Prices, University of Chicago.

Fifielda, S.G.M. \& Jetty, J. (2008). Further evidence on the efficiency of the Chinese stock markets: A note. Journal of Research in International Business and Finance, 22, pp. 351-361.

Godsill, S., Doucet, A. \& West, M. (2004). Monte Carlo Smoothing For Non-Linear Time Series. Journal of the American Statistical Association, 199, pp. 156-168.

Gordon, M.J. (1959). Dividends, earnings and stock prices. Review of Economics and Statistics, 41, pp. 99-105.

Hasanov, M. \& Omay, T. (2007). Are the transition stock market efficient? Evidence from non-linear unit root tests. Central Bank Review, 2, pp. 1-12.

Kapetanios, G., Shin, Y. \& Snell, A. (2003). A testing for a unit root in the non-linear star framework. Journal of Econometrics, 112, pp. 359-379.

Keim, D. \& Stambaugh, R. (1986). Predicting returns in stock and bond markets. Journal of Financial Economics, 17, pp. 357-390.

Kendall, M.G. (1953). The analysis of economic time series, Part 1: Prices. Journal of the Royal Statistical Society, 116, pp. 11-25.

Kim, C.J., Nelson, C.R. \& Startz, R. (1998). Testing for mean reversion in heteroscedastic data based on Gibbs sampling augmented randomisation. Journal of Empirical Finance, 5, pp. 131-157.

Kim, J. \& Stoffer, D.S. (2008). Fitting stochastic volatility models in the presence of irregular sampling via particle methods and the EM algorithm, Journal of Time Series Analysis, 29(5), pp. 811-833.

Lin, X., Fei, F. \& Wang, Y. (2011). Analysis of the efficiency of the Shanghai stock market: A volatility perspective. Physica A, 390, pp. 3486-3495.

Liu, T. (2010). Stock market development and market efficiency on China stock market. Journal of Chinese Economics and Finance, 3, pp. 5-14.

Lo, A.W. \& Mackinlay, A.C. (1988). Stock market prices do not follow random walks: Evidence from a simple specification test. The Review of Financial Studies, 1(1), pp. 41-66.

Lumsdaine, R.L. \& Papell, D.H. (1997). Multiple trend breaks and the unit root hypothesis. The Review of Economics and Statistics, 79, pp. 212-218.

Ma, S. \& Barnes, M.L. (2001), Are China's stock market really weak-form efficient. Discussion Paper No. 0119. Available: www.adelaide.edu.au.

Malkiel, B.G. (2003). The Efficient Market Hypothesis and its critics. Journal of Economic Perspective, 17, pp. 59-82.

Nakamura, T. \& Small, M. (2006). Tests of the random walk hypothesis for financial data. Physica A, 377, pp. 599-615.

Naryan, P. \& Smith, R. (2004). Is South Korea's stock market efficient? Applied Economic Letters, 11, pp. $707-710$. 
Nkemnole, દ.B. Abass, 0, \& Kasumu, R.K (2013). Parameter estimation of a class of Hidden Markov Model with diagnostics. Journal of Modern Applied Statistical Methods, 12(1), pp. 181-197.

Nkemnole, E.B. \& Abass, 0. (2015), A t-distribution based particle filter for univariate and multivariate stochastic volatility models. Nigerian Mathematical Society, 34(2), pp. 227-242.

Niederhoffer, V. \& Osborne, M.F.M. (1966). Market making and reversal on the stock exchange. Journal of American Statistical Association, 61(316), pp. 897-916.

Nwidobie, B.M. (2014). The random walk theory: An empirical test in the Nigerian Capital Market. Asian Economic and Financial Review, 4(12), pp. 1840-1848.

Osaze, B.E. (2007). Capital markets: African and Global. Lagos: Book House.

Pagan, A.R. \& Schwert, G.W. (1990). Alternative models for conditional stock volatility. Journal of Econometrics, 45, pp. 267-290.

Sharma J.L. \& Kennedy, R.E. (1977). A comparative analysis of stock price behavior on the Bombay, London, and New York stock exchanges. Journal of Financial and Quantitative Analysis, 12 (3), pp. 391413.

Shephard, N. (1996). Statistical aspects of ARCH and stochastic volatility. In D.R. Cox, D.V. Hinkley \& $0 . \varepsilon$. Barndorff- Nielsen (eds.). Time Series Models: London: Chapman and Hall (pp. 1-67).

Shumway, R.H. \& Stoffer, D.S. (2006). Time Series Analysis and its Applications: Springer, New York.

Song, S. \& Jin, W. (1995). Empirical research on efficiency of Shanghai stock market. Economist, 4, pp. 107-113.

Taylor, S.J. (1986). Modeling Financial Time Series. Chichester: Wiley.

Taylor, S.J. (1982). Financial returns modelled by the product of two stochastic Processes - a study of daily sugar prices, 1961-1979. In 0.D. Anderson (ed.) Time Series Analysis: Theory and Practice, 1. New York: Elsevier Science Publishing (pp. 203-226)

Usman, S. (1998). Comparison of the Nigerian capital market with foreign capital markets and lessons therefrom as we approach 2010. Nigeria Financial Review, 7(1), pp. 70-79.

Wu, S. (1996). Efficiency analysis of China stock market. Economic Research, 4, pp. 13-19.

Zaubia, K.A. \& Nahlehb, M.A. (2010). Financial market efficiency: Empirical evidence from some Middle East and North Africa Countries (MENA). International Research Journal of Finance and Economics, 49, pp. 173-184.

Zivot, E. \& Andrews, D.W.K. (1992).Further evidence on the great crash, the oil-price shock, and the unit-root hypothesis. Journal of Business and Economic Statistics, 10, pp. 251-270. 